\title{
TABLE OF LEGISLATION AND REGULATIONS
}

\section{US FEDERAL LAWS}

5 U.S.C. $§ 552$

5 U.S.C. $\$ 552 \mathrm{a}$

5 U.S.C. $§ 552(\mathrm{a})(3)$

5 U.S.C. $\S 552 \mathrm{a}(\mathrm{b})(2),(8)$

5 U.S.C. $\S 552 \mathrm{a}(\mathrm{d})(1),(2)$

5 U.S.C. $\S 552 \mathrm{a}(\mathrm{e})(1)$

5 U.S.C. $\$ 552 \mathrm{a}(\mathrm{e})(4)$

5 U.S.C. $\$ 552 \mathrm{a}(\mathrm{e})(6)$

5 U.S.C. $\$ 552(\mathrm{~b})$

5 U.S.C. $§ 552(\mathrm{~b})(3)(\mathrm{A})$

5 U.S.C. $\S 552(\mathrm{~b})(3)(\mathrm{B})$

5 U.S.C. $\S 552(\mathrm{~b})(4)$

5 U.S.C. $\S 552(\mathrm{~b})(6)$

5 U.S.C. $\S 552(\mathrm{~b})(7)(\mathrm{C})$

11 U.S.C. $§ 365(\mathrm{n})$

13 U.S.C. $\$ 9$

15 U.S.C. $\$ 1$

15 U.S.C. $§ 45$

17 U.S.C. $§ 101$

17 U.S.C. § 102(a)

17 U.S.C. $\$ 106$

17 U.S.C. $\$ 504(\mathrm{c})(1)$

17 U.S.C. $\$ 504(\mathrm{c})(2)$

17 U.S.C. $§ 505$

18 U.S.C. § 1832

21 U.S.C. $\$ 355(\mathrm{k})(3)$

29 U.S.C. $\$ \S 1181-1182$ (Supp. III 1997)

35 U.S.C. $\$ 100(\mathrm{~b})$

35 U.S.C. $§ 101$ 81, 89-91, 93-4, 108, 123, 187-8

35 U.S.C. $\S \S 200-212$

35 U.S.C. $\S \S 202-203$

35 U.S.C. $\$ 202(\mathrm{c})(1)$

35 U.S.C. $\$ 202(\mathrm{c})(2)$

35 U.S.C. $\$ 202(\mathrm{c})(3)$

35 U.S.C. $\$ 202(\mathrm{c})(4)$

35 U.S.C. $\$ 202$ (c) (5)

35 U.S.C. $\$ 202(\mathrm{c})(7)($ A)

35 U.S.C. § $202(\mathrm{c})(7)(\mathrm{B})-(\mathrm{C})$

35 U.S.C. $§ 203$

35 U.S.C. § 204

35 U.S.C. § 209
197, 279

278

279

278

278

279

279

278

280

279

279

279

279

280

34

282

156

156, 273

185

184

63

54

55

55

186

290

183

188

141

141

141-2

142

142

143

141

145

146

143, 145

145

138
35 U.S.C. § 209(d)(1)

35 U.S.C. § 271(a)

35 U.S.C. § 271(e)

35 U.S.C. § 271(e)(1)

42 U.S.C. § $242 \mathrm{~b}$

42 U.S.C.S. § $242 \mathrm{~b}$

42 U.S.C.S $§ 242 \mathrm{k}$

42 U.S.C.S. § 2421

42 U.S.C. $\S 242 \mathrm{~m}(\mathrm{~d})$

42 U.S.C. § $300 \mathrm{gg}-53$ (a)

42 U.S.C. $\S 2000 \mathrm{ff}-5(\mathrm{C})$

42 U.S.C. § 17921

42 U.S.C. $\$ 17932$

44 U.S.C. § 3501

44 U.S.C. § 3504(g)

44 U.S.C. § 3541 et seq.

143,145

63

149

149

282

282

282

282

282

225

225

229

183

282

282

228

\section{US FEDERAL REGULATIONS}

16 C.F.R. § 318.4 (FTC)

229

21 C.F.R. pts 50 and 56

219

37 C.F.R. $\$ 401.6$ and $401.14(\mathrm{j})$

37 C.F.R. § 401.8(b)

37 C.F.R. $§ 401.14(\mathrm{c})(1)$

37 C.F.R. $\S 401.14(\mathrm{c})(2)$

37 C.F.R. § 401.14(c)(3)

37 C.F.R. § 401.14(d)(1)

37 C.F.R. $\$ 401.14(d)(2)-(3)$

37 C.F.R. § 401.14(e)(1)

37 C.F.R. § 401.14(f)(2)

37 C.F.R. § 401.14(i)

37 C.F.R. § 401.14(k)(1)

37 C.F.R. $§ 401.14(\mathrm{k})(2)-(3)$

45 C.F.R. Pts. $160 \& 162$

42 C.F.R. Parts 412, 413, 422, and 495

143

141

141

142

142

142

142

142

141

145

145

146

183

229

$\begin{array}{ll}42 \text { C.F.R. } \S 495.24(\mathrm{c})(8)(\mathrm{ii})(\mathrm{A})-(\mathrm{F}) & \mathbf{2 8 7} \\ 45 \text { C.F.R. pt. } 2 & \mathbf{2 1 8}\end{array}$

45 C.F.R. pt. 46

219

45 C.F.R. \$ 46.101- 46.124

45 C.F.R. § 106.103

45 C.F.R. $\S 46.116(b)$ and (c) $\quad 216$ 


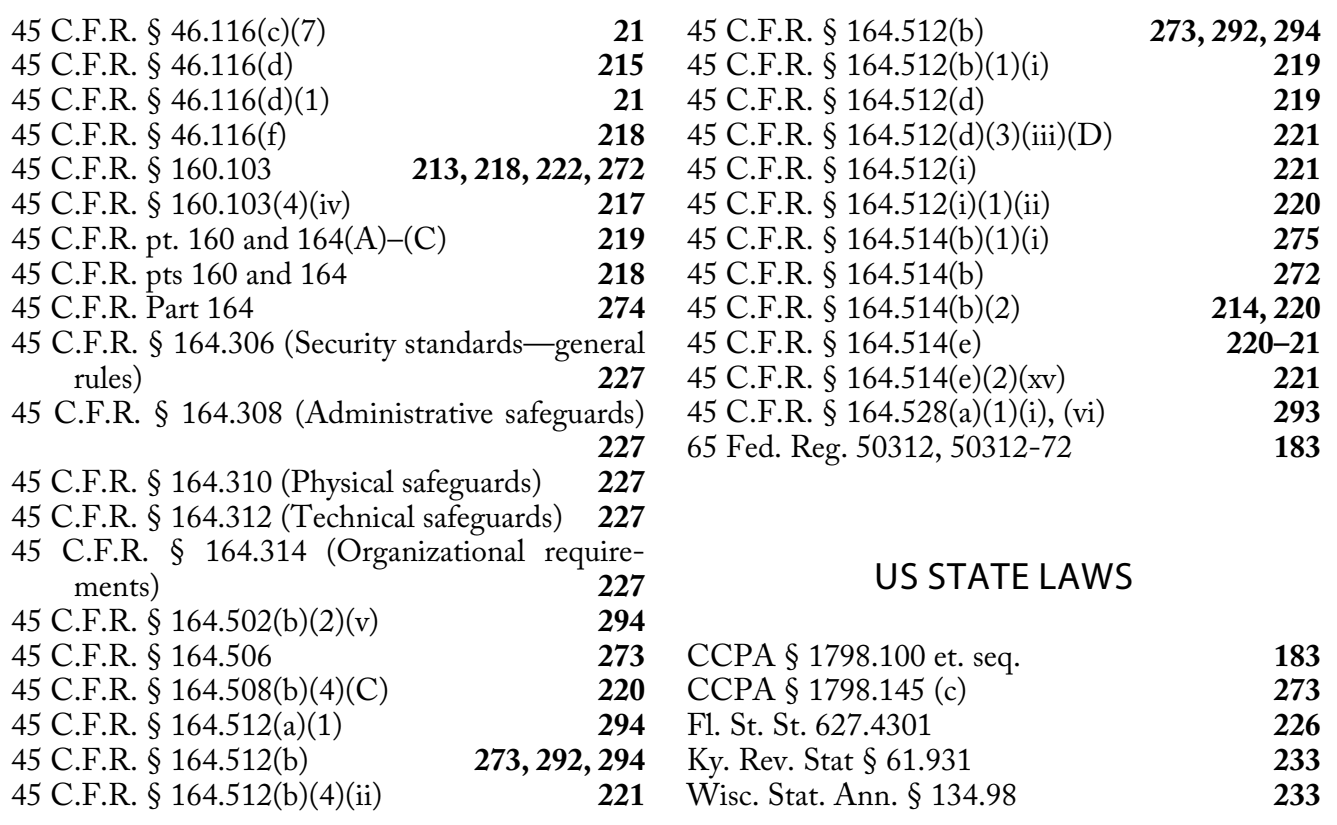

